\title{
Stability Analysis of Seed Yield of Ethiopian Caraway (Trachyspermum ammi L. Sprague ex Turrill) Genotypes in Multi-Environment Trials
}

\author{
Endalkachew Aklilu ${ }^{1 *}$ Asmamaw Bidir ${ }^{2} \quad$ Hayat Yasin $^{3} \quad$ Azeze Wubie $^{4} \quad$ Zeynu Tahir $^{5}$ \\ Berhanu Fentie $^{6} \quad$ Misganaw Gelaye $^{7} \quad$ Amare Tsehay $^{8}$ Anteneh Adem ${ }^{9}$ Melkie Desalign ${ }^{10}$ \\ Yimama Ali ${ }^{11} \quad$ Girmachew Wubie ${ }^{12}$ \\ Gondar Agricultural Research Center, P. O. Box, 1337, Gondar, Ethiopia
}

\begin{abstract}
Twelve Ethiopian caraway genotypes were evaluated in eight environments in Ethiopia during 2014 and 2015 under rain fed condition. The field experiment was laid out using randomized complete block design with three replications. The objective of this experiment was to select high yielding and stable Ethiopian caraway genotypes with nonparametric methods. Combined analysis of variance was performed and ten rank-based nonparametric stability parameters were measured. A pooled analysis variance for seed yield indicated that there were highly significant $(\mathrm{P}<0.001)$ differences for main effects of genotype, environment and their interaction. The results of principal component analysis revealed that the stability statistics and yield were classified into three groups and related to two contrasting concept of stability. In this study, TOP and rank-sum were found to be useful measures for simultaneously selecting high yield and stable cultivars. These measures selected Gondar 027-2001 and Gondar 023-2000 that gave 2254.7 Kg ha-1 and 2186.1 Kg ha-1 seed yield respectively, as stable and the National Variety Release Committee has released these genotypes as the first Ethiopian caraway varieties for production in 2017. Keywords: Ethiopian caraway, nonparametric stability statistics
\end{abstract}

DOI: $10.7176 / F S Q M / 97-06$

Publication date:May $31^{\text {st }} 2020$

\section{Introduction}

Ethiopian caraway (Trachyspermum ammi L. Sprague ex Turrill) is an annual medicinal plant belonging to Apiaceae family. It is cultivated in India, Iran, Pakistan, Egypt, and Ethiopia (Dawit et al., 2003; Tomar and Malik, 2014). It is erect and branched cross-pollinated plant. Ethiopian caraway, also named as Bishop's weed (English) and Ajowan (Hindi), has white flowers and small gray brownish seeds (Tomar and Malik, 2014). Its seeds are widely used for medicinal and food flavoring purposes (Dwivedi et al., 2012). The seed revealed to have stimulant, carminative, diuretic, antimicrobial, nematicidal, antihypertensive, antitussive, broncho dilatory, antioxidant and hypolipidemic effects (Bairwa et al., 2012; Zarshenas et al., 2014).

In Ethiopia, 5,887 tons Ethiopian caraway and black cumin were harvested from 9,204 ha of land and both cumin's are one of the export spice commodities ranked second next to ginger in spice export earnings accounted for $13.7 \%$ and $62 \%$ respectively, in 2006-2010 (MoARD, 2010, 2003). Several improved technologies including improved varieties and suitable agronomic practices had been generated and distributed to different agro ecologies to enhance productivity of lowland and highland spices in Ethiopia (Hailemichael et al., 2016). Despite its economic importance, Ethiopian caraway received less attention to improve its production and productivity and remained underutilized spice crop in Ethiopia. Research work that has been carried out so far is limited to collection and maintenance of germplasms and no significant effort applied on genetic improvement and agronomic practices. As to my knowledge, until the present, no improved Ethiopian caraway variety has been released in the country.

Most crop improvement programs aim at selecting of genotypes for maximum yield. In parallel with improving the yield, a new improved variety should have consistent yield performance across a range of environments, which is considered as stable or widely adaptable. Genotypes are commonly evaluated on multienvironments to select high yielder and stable cultivars across diverse environments. In evaluating genotypes in multi-environment trials, the effects of genotype and genotype by environment interaction are the most relevant (Yan and Kang, 2003). Moreover, significant interaction of genotype by environment creates trouble in selecting superior cultivars in stability and yield performance (Kang, 1990; Magari and Kang, 1993). In this case, yield stability analyses become pertinent (Hussein et al., 2000). There are many parametric and nonparametric statistical methods to determine yield stability. The parametric stability methods are preferred under certain statistical assumptions, like normal distribution of errors. However, if these assumptions are violated, parametric stability methods may not perform well (Huehn, 1990), but nonparametric methods can be quite reliable (Truberg and Huehn, 2000). Nonparametric stability methods provide useful alternative to parametric methods, since the nonparametric measures do not require statistical assumptions such as the distribution of observed values (Huehn, 1990). Non parametric procedures proposed by Huehn (1979), Nassar and Huehn (1987), Kang (1988), Fox et al. (1990) and Thennarasu (1995) classify genotypes as stable if they rank similarly across environments based on 
mean yield. Huehn (1979) and Nassar and Huehn (1987) proposed four nonparametric stability statistics; (1) $\mathrm{Si}(1)$ is the mean of the absolute rank differences of a genotype over the $\mathrm{n}$ environments; (2) $\mathrm{Si}(2)$ is the variance among the ranks over the n environments; (3) $\mathrm{Si}(3)$ and $\mathrm{Si}(6)$ are the sum of the absolute deviations and sum of squares of rank for each genotype relative to the mean of ranks, respectively. A genotype with lowest value of these statistics is considered to be the most stable. Using ranks of adjusted yield means of genotypes in each environment, Thennarasu (1995) proposed NPi(1), NPi(2), NPi(3) andNPi(4) nonparametric statistics and defined stable genotypes as those whose position in relation to the others remained unaltered in the set of environments assessed. A genotype with lowest value of these statistics is considered most stable. Fox et al. (1990) measure the frequency of each that ranked in the top, middle, and bottom third (TOP) of all tested genotypes across environments. A genotype frequently appeared in the top third for yield rank is considered as the most stable. Kang (1988) nonparametric stability parameter applies both yield rank and Shukla's Stability variance (Shukla, 1972). The genotypes that score lowest rank-sum are the most preferred ones. Studying the relationship among nonparametric stability parameters using rank correlations is pertinent to identify the appropriate stability parameters (Mohammadi et al., 2009) and to relate stability parameters with statistic and dynamic concepts of stability (Becker and Leon, 1988). The objectives of the present study were to perform yield stability analysis using non parametric parameters, to study the relationships among stability parameters, and to select high yielding and stable Ethiopian caraway varieties.

\section{Materials and methods}

Planting materials and test environments

The Ethiopian caraway landraces were originally collected from different Ethiopian caraway growing areas of Amhara region and then morphologically characterized. Then twelve accessions were selected from previous preliminary yield trials that had been conducted in consecutive years. Since there was no registered variety, standard check was not used. Twelve Ethiopian caraway accessions were tested in 8 environments (year and location combinations) during 2014 and 2015 in Ethiopia under rain fed condition. The testing environments and genotypes are described in Table 1 and 3, respectively.

Experimental layout and field management

In all environments, the field experiments were laid out using randomized complete block design with three replications. Each genotype was planted on a plot size of $1.8 \mathrm{~m}$ long with five rows of $30 \mathrm{~cm}$ apart. Thinning was done to have $15 \mathrm{~cm}$ space between plants. Nitrogen was applied at rate of $45 \mathrm{~kg}$ ha-1at planting and P2O5 was applied at rate of $30 \mathrm{~kg}$ ha-1, half at planting and half before flowering. At Kulumsa, supplementary furrow irrigation was provided at flowering stage for two times on ten days interval. Seed yield data collected from central three rows were converted into $\mathrm{kg} \mathrm{ha}^{-1}$.

Statistical analysis

Seed yield data were subjected to combined analysis of variance (ANOVA) using GLM procedure of SAS statistical package (SAS, 2002). Variance homogeneity was tested using Barttlet test and the variance across eight environments varied significantly. Hence, ten nonparametric stability statistics, $\mathrm{Si}(1), \mathrm{Si}(2), \mathrm{Si}(3)$ and $\mathrm{Si}(6)$ (Huehn, 1979; Huehn and Nassar, 1987), NPi(1), NPi(2),NPi(3) and NPi(4) (Thennarasu, 1995), rank-sum (RS) (Kang, 1988), TOP (Fox et al, 1990) were computed using R statistical package called "phenability" (Branco, 2015). Spearman rank correlation coefficients among nonparametric stability parameters and with mean yield were produced using SAS statistical package (Steel and Torrie, 1980; SAS, 2002). To further study the association among stability parameters and with yield, principal component analysis (PCA) was performed using rank correlation matrix in Genstat (Genstat, 2015). 
Table 1: Description of locations used for evaluation of 12 Ethiopian caraway genotypes in Ethiopia

\begin{tabular}{|c|c|c|c|c|c|c|c|c|c|}
\hline \multirow[t]{2}{*}{ Locations } & \multirow[t]{2}{*}{ Year } & \multirow{2}{*}{$\begin{array}{l}\text { Seed yield } \\
\left(\mathrm{kg} \mathrm{ha}^{-1}\right)\end{array}$} & \multicolumn{2}{|c|}{ Coordinate } & \multirow{2}{*}{$\begin{array}{l}\text { Altitude } \\
\text { (M. asl) }\end{array}$} & \multirow{2}{*}{$\begin{array}{l}\text { Mean } \\
\text { rainfall } \\
(\mathrm{mm})\end{array}$} & \multicolumn{2}{|c|}{$\begin{array}{c}\text { Temperature } \\
\left({ }^{\circ} \mathrm{C}\right)\end{array}$} & \multirow[t]{2}{*}{ Soil type } \\
\hline & & & Latitude $(\mathrm{N})$ & Longitude(E) & & & & $\max$ & \\
\hline \multirow[t]{2}{*}{ Takusa } & 2014 & 3282.775 & $12^{0} 10^{\prime} 11^{\prime \prime}$ & $37^{\circ} 01^{\prime} 05^{\prime \prime}$ & 1840 & 870 & 15 & 28 & Vertisol \\
\hline & 2015 & 2352.933 & & & & & & & \\
\hline \multirow{2}{*}{ Dembia } & 2014 & 1797.458 & $12^{0} 30^{\prime} 49^{\prime \prime}$ & $37^{0} 33^{\prime} 39^{\prime \prime}$ & 1920 & 1000 & 18 & 27 & Vertisol \\
\hline & 2015 & 1909.867 & & & & & & & \\
\hline Chefa & 2015 & 857.1333 & $10^{0} 57^{\prime} 06^{\prime \prime}$ & $39^{\circ} 47^{\prime} 03^{\prime \prime}$ & 1400 & 850 & 21 & 36 & Vertisol \\
\hline Debre-ziet & 2015 & 1919.225 & $8^{\circ} 44^{\prime} 18^{\prime \prime}$ & $38^{0} 98^{\prime} 15^{\prime \prime}$ & 1900 & 851 & 10.9 & 29.4 & $\begin{array}{l}\text { Eutric } \\
\text { Vertisols }\end{array}$ \\
\hline Kulumsa & 2015 & 3002.242 & $08^{\circ} 01^{\prime} 00^{\prime \prime}$ & $39^{\circ} 09^{\prime} 32^{\prime \prime}$ & 2200 & 820 & 11 & 23 & $\begin{array}{l}\text { Haplic } \\
\text { Xerosols }\end{array}$ \\
\hline Assosa & 2015 & 841.5833 & $10^{\circ} 30^{\prime} 05^{\prime \prime}$ & $35^{\circ} 20^{\prime} 23^{\prime \prime}$ & 1400 & 1100 & 14 & 27.8 & Vertisol \\
\hline
\end{tabular}

\section{Results and discussion}

Combined analysis of variance

A combined ANOVA (Table 2) for seed yield of 12 Ethiopian caraway genotypes studied across eight environments indicated that there were significant $(P<0.001)$ differences for the effect of genotype $(G)$, environment $(\mathrm{E})$ and $\mathrm{G} x \mathrm{E}$ interaction. Out of total variation, environment contributed maximum variance $(79.3 \%)$, indicating its largest effect on seed yield than the effect of genotype (1.11\%) and G x E interaction (9.24\%). In multi environment trials, variance of environment is known to be largest $(80 \%)$ while $\mathrm{G} \times \mathrm{E}$ interaction and genotype are usually small (Yan and Kang, 2003). The largest environmental variance might be resulted from the agro-ecological variation among test locations (Table 1). However, the most relevant for genotype evaluation are the genotypic and G x E interaction effects and environment effect is usually ignored (Yan and Kang, 2003). In this study, the G x E effect exceeded the genotype effect 8 times, showing significant $G \times E$ interaction effect suggesting the possible presence of different mega environments with different top-yielding genotypes and the genotypes performed variably across environments (Yan and Kang, 2003). Magari and Kang (1993) and Kang (1990) demonstrated that significant interaction of genotype by environment creates trouble in selecting stable cultivars. Hence, selecting superior genotypes depending on stability and yield performance would be appropriate. Table 2: Combined analysis of variance (ANOVA) table

\begin{tabular}{lllll}
\hline Source & DF & Anova SS & Mean Square & Variance component (\%) \\
\hline Replication(E) & 16 & 1511758.3 & $94484.9^{\text {ns }}$ & 10.35 \\
Environment (E) & 7 & 197214613.8 & $28173516.3 * * *$ & 79.3 \\
Genotype (G) & 11 & 6507771.4 & $591615.6^{* * *}$ & 1.11 \\
Gx E & 77 & 25778798.7 & $334789.6^{* * *}$ & 9.24 \\
Pooled error & 176 & 11784026.2 & 66954.7 & \\
\hline Total & 287 & 242796968.4 & & 100 \\
\hline
\end{tabular}

$C V=12.9$, Mean $=1995.4, * * *$ Significant at the 0.001 probability level. ${ }^{n s}$ Non-Significant at the 0.05 probability

Seed yield performance

The average seed yield of Ethiopian caraway genotypes across environments ranged from $1762.9 \mathrm{~kg}$ ha- 1 for genotype Adet 12-2000 (G2) to $2254.7 \mathrm{~kg}$ ha-1for genotype Gondar 027-2001 (G4) (Table 3). The maximum environmental mean seed yield was obtained from Takusa-2014 (3282.8 kg ha-1). The minimum environmental mean seed yield was obtained from Assosa-2015 (841.6 kg ha-1) and Chefa-2015 (857.1 kg ha-1) (Table 3). Heidaria et al. (2016) found that seed yield of Ajowan (Trachyspermum ammi L.) accessions collected in Iran ranged from $1432.1 \mathrm{~kg}$ ha-1 to $4539.2 \mathrm{~kg}$ ha- 1 . 
Table 3:Combined mean seed yield of 12 Ethiopian caraway genotypes studied in 8 environments

\begin{tabular}{lllllll}
\hline No & Code & Genotype & $\begin{array}{l}\text { Mean seed } \\
\text { yield }\left(\mathrm{kg} \mathrm{ha}^{-1}\right)\end{array}$ & No. & Environments & $\begin{array}{l}\text { Mean seed } \\
\text { yield }\left(\mathrm{kg} \mathrm{ha}^{-1}\right)\end{array}$ \\
\hline 1 & G1 & Gondar 002-2002 & 1919.2 & 1 & Takusa-2014 & 3282.8 \\
2 & G2 & Adet 12-2000 & 1762.9 & 2 & Takusa-2015 & 2352.9 \\
3 & G3 & Gondar 0011-2000 & 2079.6 & 3 & Dembia-2014 & 1797.5 \\
4 & G4 & Gondar 027-2001 & 2254.7 & 4 & Dembia-2015 & 1909.9 \\
5 & G5 & Gondar 010-2002 & 1840.3 & 5 & Chefa-2015 & 857.1 \\
6 & G6 & Gondar 018-2000 & 1830.1 & 6 & Debre-ziet-2015 & 1919.2 \\
7 & G7 & Gondar 025-2000 & 1995.6 & 7 & Kulumsa-2015 & 3002.2 \\
8 & G8 & Gondar 026-2000 & 1903.9 & 8 & Assosa-2015 & 841.6 \\
9 & G9 & Adet 18-2000 & 2154.0 & & & \\
10 & G10 & Gondar 004 & 2096.7 & & & \\
11 & G11 & Gondar 023-2000 & 2186.1 & & & \\
12 & G12 & Gondar 007-2002 & 1921.7 & & & \\
\hline
\end{tabular}

Nonparametric stability analysis

The value of ten nonparametric stability statistics using seed yield and their rank based on the value were presented in Table 4 and 5, respectively. The significant tests, Z1 and Z2, values for $\mathrm{Si}(1)$ and $\mathrm{Si}(2)$ were calculated using ranks of adjusted data for each genotype and added over to get Z1 and Z2 sum, respectively (Table 4) (Nassar and Huehn, 1987). The critical value of $\chi 2(21.03)(P<0.05, \mathrm{df}=11)$ exceeded both $Z$ sum values, showing that there were no significant differences in rank stability among genotypes. Besides, none of any genotype had higher $\mathrm{Z}$ value than the critical value $\chi 2(8.2)(P<0.05, \mathrm{df}=1)$, indicating all genotypes performed significantly stable, relative to others. G1 and G12were considered as the most stable genotype since they had the minimum value of both Nassar and Huehn's (1987) statistics, Si (1) and Si(2). The highest yielding genotype, G4, ranked the third most stable according to both stability statistics (Table 5). G5 showed maximum value of $\mathrm{Si}(1)$ and $\mathrm{Si}(2)$, indicating to be the most unstable genotype. $\mathrm{Si}(3)$ and $\mathrm{Si}(6)$ stability statistics combine yield and stability performance and the lowest values of these statistics indicate the most stable genotype (Huehn, 1979). Both Si (3) and Si(6) statistics identified G2 and G6 as the most stable and G9 as the most unstable genotypes.

Thennarasu's (1995) nonparametric statistics, NPi(1), NPi(2), NPi(3) andNPi(4), consider a genotype with lowest value of these statistics as the most stable. According to NPi(1), G1 and G12 scored the lowest value, hence they were the most stable genotypes and G5 and G11 were the most unstable. G1 showed small value of NPi(2), indicating to be the most stable, followed by G8 and G12. Like NPi(1), NPi(3) selected G1 and G12 as the most stable. Statistics NPi(4) identified G6, G3 and G2 as the most stable genotypes. Three of Thennarasu's (1995) statistics, $\mathrm{NPi}(2), \mathrm{NPi}(3)$ and $\mathrm{NPi}(4)$ indicated that the highest yielding genotypes, G4 and G11 were the most unstable (Table 5). Similarly, Yong-Jian et al. (2010) found that NPi(2), NPi(3) and NPi(4) identified higher yielding genotypes as unstable in maize multi-environment trials.

Table 4: The value of nonparametric stability statistics computed for 12 genotypes

\begin{tabular}{|c|c|c|c|c|c|c|c|c|c|c|c|c|c|}
\hline $\begin{array}{l}\text { Genotypic } \\
\text { code }\end{array}$ & $\begin{array}{l}\text { Mean yield } \\
\left(\mathrm{kg} \mathrm{ha}^{-1}\right)\end{array}$ & $\mathrm{S}_{\mathrm{i}}^{(1)}$ & $\mathrm{Zl}$ & $\mathrm{S}_{\mathrm{i}}^{(2)}$ & $\mathrm{Z2}$ & $\mathrm{S}_{\mathrm{i}}^{(3)}$ & $\mathrm{S}_{\mathrm{i}}^{\left({ }^{(6)}\right.}$ & $\mathrm{NP}_{i}^{(1)}$ & $\mathrm{NP}_{i}^{(2)}$ & $\mathrm{NP}_{\mathrm{i}}^{(3)}$ & $\mathrm{NP}_{\mathrm{i}}^{(4)}$ & TOP & RS \\
\hline G1 & 1919.19 & 3.11 & 1.20 & 7.12 & 1.21 & 11.10 & 3.41 & 1.88 & 0.21 & 0.32 & 0.018 & 1 & 11 \\
\hline G2 & 1762.92 & 4.61 & 0.65 & 16.12 & 0.93 & 15.77 & 4.67 & 2.88 & 0.30 & 0.46 & 0.018 & 1 & 14 \\
\hline G3 & 2079.57 & 4.43 & 0.33 & 15.07 & 0.52 & 12.62 & 3.54 & 3.00 & 0.40 & 0.56 & 0.017 & 2 & 17 \\
\hline G4 & 2254.71 & 3.68 & 0.14 & 11.98 & 0.00 & 10.97 & 2.54 & 2.13 & 1.06 & 0.86 & 0.057 & 5 & 11 \\
\hline G5 & 1840.30 & 5.11 & 2.07 & 18.27 & 2.13 & 22.57 & 4.86 & 3.63 & 0.56 & 0.60 & 0.043 & 2 & 11 \\
\hline G6 & 1830.14 & 4.04 & 0.01 & 12.12 & 0.00 & 12.11 & 3.89 & 2.63 & 0.33 & 0.39 & 0.013 & 0 & 15 \\
\hline G7 & 1995.61 & 4.11 & 0.03 & 12.70 & 0.03 & 7.14 & 2.00 & 2.63 & 0.44 & 0.56 & 0.024 & 1 & 12 \\
\hline G8 & 1903.85 & 3.96 & 0.00 & 11.41 & 0.01 & 15.39 & 4.15 & 2.38 & 0.28 & 0.40 & 0.027 & 1 & 17 \\
\hline G9 & 2153.97 & 4.50 & 0.45 & 13.93 & 0.21 & 9.69 & 2.75 & 3.00 & 0.50 & 0.65 & 0.027 & 3 & 14 \\
\hline G10 & 2096.74 & 3.82 & 0.04 & 11.98 & 0.00 & 7.25 & 2.37 & 2.63 & 0.48 & 0.66 & 0.051 & 3 & 11 \\
\hline G11 & 2186.14 & 4.71 & 0.88 & 15.36 & 0.62 & 9.50 & 2.50 & 3.25 & 0.81 & 0.73 & 0.071 & 4 & 11 \\
\hline G12 & 1921.67 & 3.21 & 0.92 & 7.14 & 1.20 & 16.67 & 4.48 & 2.00 & 0.29 & 0.32 & 0.023 & 1 & 12 \\
\hline Total & & & 6.71 & & 6.88 & & & & & & & & \\
\hline \multicolumn{14}{|c|}{$\begin{array}{l}\text { statistics } \operatorname{Si}\left({ }^{1}\right) \text { and } \operatorname{Si}\left({ }^{2}\right) \\
E\left(\operatorname{Si}\left({ }^{1}\right)\right)=3.972 E\left(\operatorname{Si}\left({ }^{2}\right)\right)=11.916 \\
\left.\operatorname{Var}\left(\operatorname{Si}\left({ }^{1}\right)\right)=0.623 \operatorname{Var}\left(\operatorname{Si}^{2}\right)\right)=18.974 \\
\chi 2 \mathrm{sum}=21.03 \chi 2 \mathrm{Z1Z2}=8.2 \\
\text { Yield mean }=1995.40 \mathrm{~kg} \mathrm{ha}-1\end{array}$} \\
\hline
\end{tabular}


TOP stability measure chose the best yielding genotypes G4 and G11 as the most stable followed by G9 and G10, since they ranked in the top third in the majority of environments (Fox et al.,1990) (Table 5 and 6). According to Temesgen et al. (2015), TOP measure identified high yielding genotypes to be the most stable in faba bean. The undesirable genotypes identified by TOP measure were G6. According to Kang (1988), nonparametric stability statistics, genotypes that score lowest rank-sum (RS) value are the most preferred ones. Two best yielding (G4 and G11) and three relatively lower yielding (G10, G1, and G5) genotypes had lower rank-sum (RS) and were considered as the most stable (Table 5 and 6). G3, G6, and G8 were identified to be undesirable genotypes by the rank-sum statistic.

Table 5: Ranks of 12 Ethiopian caraway genotypes using 10 different nonparametric stability methods

\begin{tabular}{llllllllllll}
\hline $\begin{array}{l}\text { Genotypic } \\
\text { code }\end{array}$ & Yield & $\mathrm{S}_{\mathrm{i}}{ }^{(1)}$ & $\mathrm{S}_{\mathrm{i}}{ }^{(2)}$ & $\mathrm{S}_{\mathrm{i}}{ }^{(3)}$ & $\mathrm{S}_{\mathrm{i}}{ }^{(6)}$ & $\mathrm{NP}_{\mathrm{i}}{ }^{(1)}$ & $\mathrm{NP}^{(2)}$ & $\mathrm{NP}_{\mathrm{i}}{ }^{(3)}$ & $\mathrm{NP}_{\mathrm{i}}{ }^{(4)}$ & $\mathrm{TOP}$ & $\mathrm{RS}$ \\
\hline $\mathrm{G} 1$ & 8 & 1 & 1 & 5 & 3 & 1 & 1 & 1 & 4 & 5 & 1 \\
$\mathrm{G} 2$ & 12 & 10 & 10 & 1 & 1 & 6 & 4 & 5 & 3 & 5 & 3 \\
$\mathrm{G} 3$ & 5 & 8 & 8 & 9 & 9 & 7 & 6 & 7 & 2 & 4 & 4 \\
$\mathrm{G} 4$ & 1 & 3 & 4 & 6 & 11 & 3 & 12 & 12 & 11 & 1 & 1 \\
$\mathrm{G} 5$ & 10 & 12 & 11 & 10 & 7 & 9 & 10 & 8 & 9 & 4 & 1 \\
$\mathrm{G} 6$ & 11 & 6 & 5 & 2 & 2 & 5 & 5 & 3 & 1 & 6 & 4 \\
$\mathrm{G} 7$ & 6 & 7 & 6 & 8 & 5 & 5 & 7 & 6 & 6 & 5 & 2 \\
$\mathrm{G} 8$ & 9 & 5 & 3 & 7 & 6 & 4 & 2 & 4 & 8 & 5 & 4 \\
$\mathrm{G} 9$ & 3 & 9 & 7 & 12 & 12 & 7 & 9 & 9 & 7 & 3 & 3 \\
$\mathrm{G} 10$ & 4 & 4 & 4 & 3 & 8 & 5 & 8 & 10 & 10 & 3 & 1 \\
$\mathrm{G} 11$ & 2 & 11 & 9 & 11 & 10 & 8 & 11 & 11 & 12 & 2 & 1 \\
G12 & 7 & 2 & 2 & 4 & 4 & 2 & 3 & 2 & 5 & 5 & 2
\end{tabular}

Relationships among nonparametric stability statistics

The result of spearman's rank correlation shown on Table 6 indicates that only TOP parameter was significantly $(\mathrm{p}<0.01)$ and positively correlated with mean yield, indicating TOP could be importantly used for selecting genotypes with high wider adaptability in Ethiopian caraway. Strong positive correlation of mean yield with TOP has been also reported in lentil (Sabaghnia et al., 2006), bread wheat (Gebru and Abay, 2013), faba bean (Temesgen et al., 2015) and durum wheat (Mohammadi and Amri, 2008, Kaya and Turkoz, 2016) genotypes. Mean yield and TOP measure were significantly and negatively correlated with NPi(2), NPi(3), NPi(4) and $\operatorname{Si}(6)$ and these four statistics were correlated significantly and positively to each other (Table 6). Similarly Sabaghnia et al. (2006) and Mohammadi et al. (2009) have reported that yield and TOP measure were negatively correlated with $\operatorname{NPi}(2), \operatorname{NPi}(3), \mathrm{NPi}(4)$ and $\mathrm{Si}(6)$ in lentil and barley genotypes, respectively. These four statistics were correlated positively to each other in lentil and barley genotypes (Sabaghnia et al., 2006; Mohammadi et al., 2009). In this study, $\mathrm{NPi}(2), \mathrm{NPi}(3)$, and $\mathrm{NPi}(4)$ statistics were not significantly correlated with NPi(1). Similarly, absence of significant association of $\mathrm{NPi}(1)$ with the remaining NPis' was also reported in lentil and maize genotypes (Sabaghnia et al,2006; Yong-Jian et al., 2010). There were significantly $(\mathrm{p}<0.01)$ positive rank correlation among $\mathrm{Si}(1), \mathrm{Si}(2)$ and NPi (1) but these statistics were not correlated with mean yield. Sabaghnia et al. (2006), Mohammadi and Amri (2008), Mohammadi et al. (2009), and Kaya, and Turkoz (2016) have reported similar result in multi-environment trial of genotypes of different crops. In agreement with the current result, significantly positive correlation between $\mathrm{Si}(3)$ and $\mathrm{Si}(6)$ and significantly negative correlation with mean yield were indicated by Mohammadi et al. (2007a), Segherloo et al. (2008), Shah et al. (2009), and Temesgen et al. (2015). RS was not significantly correlated with mean yield and TOP. Mohammadi and Amri, (2008) reported similar result in durum wheat. According to Mohammadi et al. (2009), RS was not significantly correlated with TOP in genotypes of four studied crops.

Table 6: Spearman's rank correlation coefficient of yield and nonparametric stability statistics for 12 Ethiopian caraway genotypes tested across eight environments

\begin{tabular}{|c|c|c|c|c|c|c|c|c|c|c|}
\hline & Yield & $\mathrm{S}_{\mathrm{i}}{ }^{(1)}$ & $\mathrm{S}_{1}^{(2)}$ & $\mathrm{S}_{\mathrm{i}}^{(3)}$ & $\mathrm{S}_{\mathrm{i}}^{(6)}$ & $\mathrm{NP}_{1}^{(1)}$ & $\mathrm{NP}_{1}^{(2)}$ & $\mathrm{NP}_{i}^{(3)}$ & $\mathrm{NP}_{1}^{(4)}$ & TOP \\
\hline $\mathrm{Si}^{(1)}$ & 0.112 & & & & & & & & & \\
\hline $\mathrm{S}_{\mathrm{i}}^{(2)}$ & 0.095 & $0.963^{*} *$ & & & & & & & & \\
\hline $\mathrm{S}_{\mathrm{i}}^{(3)}$ & -0.510 & 0.489 & 0.375 & & & & & & & \\
\hline $\mathrm{Si}_{\mathrm{i}}^{(6)}$ & $-0.86^{* *} *$ & 0.209 & 0.186 & $0.741^{*} * *$ & & & & & & \\
\hline $\mathrm{NP}_{i}^{(1)}$ & -0.042 & $0.956^{* *}$ & $0.933^{* *}$ & 0.554 & 0.370 & & & & & \\
\hline $\mathrm{NP}_{i}^{(2)}$ & $-0.643^{*}$ & 0.469 & 0.525 & 0.510 & $0.748 * *$ & 0.561 & & & & \\
\hline $\mathrm{NP}_{i}\left({ }^{(3)}\right.$ & $-0.727^{*} *$ & 0.406 & 0.455 & 0.468 & $0.825^{* * *}$ & 0.515 & $0.930 * *$ & & & \\
\hline $\mathrm{NP}_{i}^{(4)}$ & $-0.622^{*}$ & 0.119 & 0.059 & 0.433 & $0.657^{*}$ & 0.166 & $0.671^{*}$ & $0.741^{*}$ * & & \\
\hline TOP & $0.837^{* * *}$ & -0.215 & -0.257 & -0.531 & $-0.895^{* *}$ & -0.356 & $-0.819 * *$ & -0.917 * * & 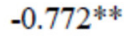 & \\
\hline RS & 0.403 & 0.110 & 0.051 & -0.114 & -0.249 & 0.054 & -0.458 & -0.411 & $-0.671^{*}$ & 0.54 \\
\hline
\end{tabular}


Principal component analysis

Principal component analysis (PCA) was computed to further investigate the relationship among nonparametric stability parameters and with mean yield. Figure 1 shows a bi plot graph of PCA1 against PCA2. The first two principal components described $80.76 \%$ (54.55\% and $26.21 \%$ by PCA1 and PCA2, respectively) of the original variance. The bi plot of the PCA1 and PCA2 divided stability parameters and mean yield into three groups (Figure $1)$.

In this study, PCA1 distinguished stability parameters and mean yield based on two contrasting concepts of stability: the static (biological) and dynamic (agronomic) concepts. The concept of both stabilities is explained in detail by Becker (1981) and Becker and Leon (1988). Regarding to static stability/biological concept, a stable genotype performs constant yield regardless of environmental variations. On the contrary, according to dynamic/agronomic stability, the yield performance of a stable genotype responds to environmental variation (Becker, 1981; Becker and Leon, 1988).

PCA1 axis clustered mean yield and parameters TOP and RS, (Group 1), at left side and these parameters were matched with the dynamic/agronomic stability concept. At right side, PCA1 axis clustered the remaining other nonparametric stability parameters, $\operatorname{Si}(1), \operatorname{Si}(2)$ and $N P i(1)$ (Group 2) and $\operatorname{Si}(3), \operatorname{Si}(6), \operatorname{NPi}(2), \operatorname{NPi}(3)$ and NPi(4)(Group 3) that matched with static/biological stability concept.

Parameters clustered in Group 1 (TOP and RS) had positive correlation among themselves and with mean yield in Ethiopian caraway genotypes (Table 6). These stability parameters, TOP and RS, are related to dynamic/agronomic stability concept. Several previous studies indicated that TOP and RS are positively associated with mean yield and are related to the dynamic concept of stability (Sabaghnia et al., 2006; Mohammadi and Amri, 2008; Flores et al., 1998; Mohammadi and Ahmed, 2013; Akcura and Kaya, 2008). Therefore, these parameters could be recommended as useful measures for cultivar selection; according to Becker (1981) and Mekbib (2002), most plant breeders are interested in selecting for high yield and stability, simultaneously.

Hence, Top, and RS could be used to select high yielding Ethiopian caraway genotypes stable to wide range of environments. In this study, Gondar 027-2001 (G4) and Gondar 023-2000 (G11) were found to be high yielding and stable based on the TOP and RM parameters that are related to dynamic concept of stability. Besides, genotype Gondar 027-2001 (G4) also ranked as third most stable based on two static concept statistics, Si(1) and NPi(1) that did not correlate with yield. According to Becker and Leon (1988), in dynamic concept of stability, stable genotype should not necessarily have a constant performance across environments. Hence, parameters associated with dynamic concept of stability could be used to identify cultivars for high potential environments. However, as pointed out by Roostaei et al. (2014), these stability parameters might drop low general adaptable but high specific adaptable genotypes.

Stability parameters clustered in group $2(\mathrm{Si}(1), \operatorname{Si}(2)$ and $\mathrm{NPi}(1))$ were correlated significantly $(\mathrm{p}<0.01)$ and positively to each other. $\mathrm{Si}(1), \mathrm{Si}(2)$ and $\mathrm{NPi}(1)$ statistics ranked genotypes for stability similarly suggesting one of these parameters can be used as an alternative to the other parameters. Statistics $\operatorname{Si}(1), \operatorname{Si}(2)$ and NPi(1) (group 2) matched with static/biological concept of stability and were not significantly correlated with mean yield, the group 1 (dynamic stability) and group 3 (static stability) statistics. In agreement with the current result, Sabaghnia et al. (2006), Kaya and Turkoz (2016) and Mohammadi and Amri (2008) indicated that Si(1), Si(2) and NPi(1) were not correlated with yield and related to static/biological concept of stability. Previous research (Nassar and Huehn, 1987; Mohammadi et al., 2007b) have also shown that Si(1)and Si(2)defined stability in the sense of homeostasis and are related to the static (biological) concept of stability. Group 2 statistics ( $\operatorname{Si}(1), \operatorname{Si}(2)$ and NPi(1)) were influenced simultaneously by both mean yield and stability. Therefore, as also reported by Sabaghnia et al. (2006), $\mathrm{Si}(1), \mathrm{Si}(2)$ and NPi(1) parameters could be used as compromise methods to select genotypes with moderate yield and high stability (Sabaghnia et al., 2006).

Three of Thennarasu's (1995) parameters (NPi(2), NPi(3) and NPi(4)), Si(3) and Si(6)clustered in group 3 had positive association to each other. Like the group 2, statistics clustered in group 3 identified stable genotypes based on the static or biological concept of stability. But unlike group 2, group 3 statistics (NPi(2), NPi(3), NPi(4), $\mathrm{Si}(3)$ and $\mathrm{Si}(6)$ ) had significantly negative correlation with mean yield. Kaya and Turkoz (2016), Mohammadi and Amri (2008), Yong-Jian et al.(2010) have indicated that NPi(2), NPi(3), NPi(4), Si(3) and Si(6) statistics matched with static concept of stability and associated negatively with mean yield. The above parameters that are selected based on only stability without considering high yielding might not be suitable, since, according to Becker (1981), plant breeders and agronomists prefer to select high yielding genotypes with wider adaptability. Besides, Mohammadi et al. (2007a), Yong-Jian et al. (2010), Kaya and Turkoz (2016) and Sabaghnia et al. (2006) reported that $\mathrm{NPi}(2), \operatorname{NPi}(3), \mathrm{NPi}(4), \mathrm{Si}(3)$ and $\mathrm{Si}(6)$ were not suitable for detecting stable and high yielding genotypes. 


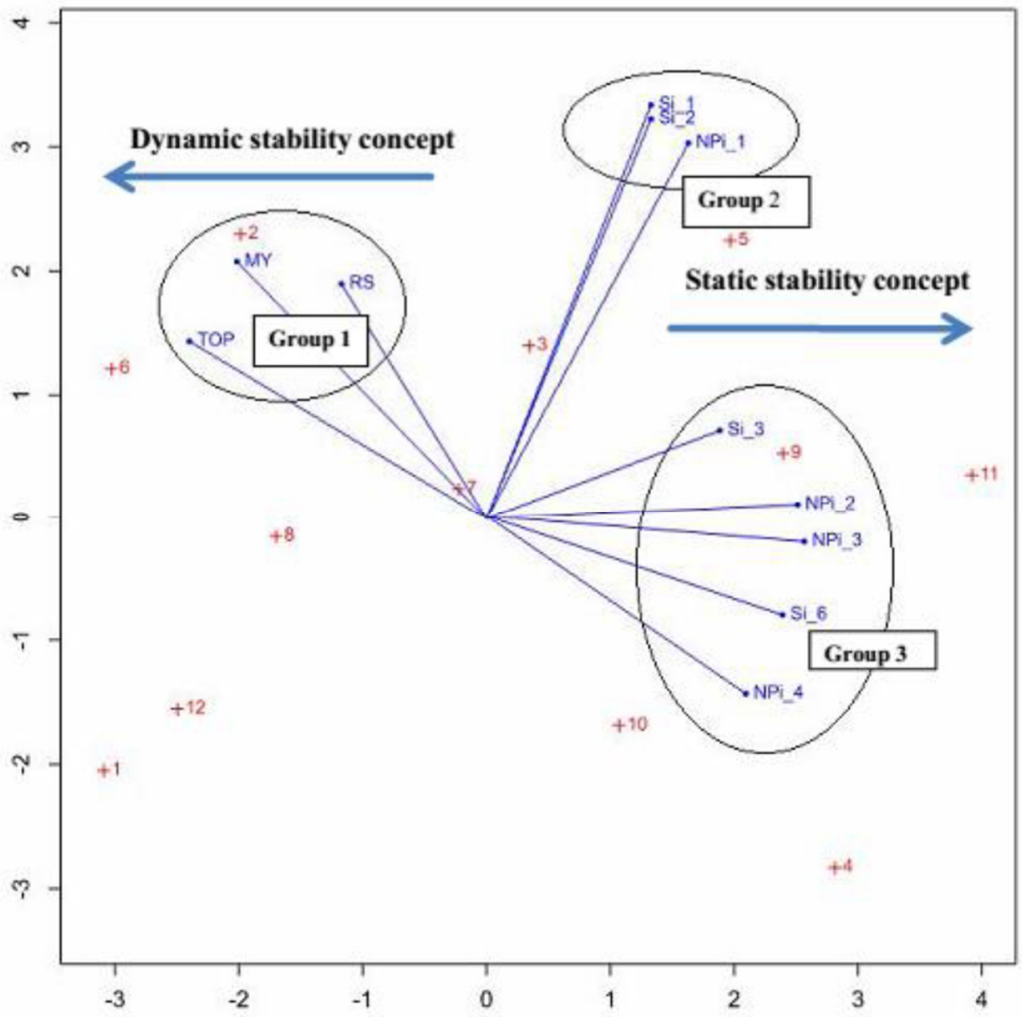

Figure 1: Biplot of PC-1 and PC-2 of the rank correlation matrix of the 10 nonparametric stability parameters with seed yield.

\section{Conclusion}

Plant breeders and farmers prefer to select high yielding genotypes with good stability. So, both yield and stability should be simultaneously considered in genotype selection. Therefore, the use of agronomic or dynamic concept of stability is better. The present study indicated that group 1 nonparametric statistics, TOP (proportion of environments at which the genotype occurred in the top third) and rank-sum (sum of ranks of mean yield and Shukla's stability variance), positively correlated with mean yield and associated with the dynamic concept of stability. This study indicated that TOP and RS nonparametric statistics could be used to select genotypes for both high yielding and better stability simultaneously, in future Ethiopian caraway breeding program. Based on TOP and RS stability measures, Gondar 027-2001 (G4) and Gondar 023-2000 (G11) were high yielding and stable genotypes. Hence, National Variety Releasing Committee under the Ministry of Agriculture and Natural Resources of Ethiopia approved the release of $027-2001(\mathrm{G} 4)$ and Gondar 023-2000 (G11) for production and named as "Dembia-01" and "Takusa-01" respectively (MoANR, 2017).

\section{Acknowledgements}

We would like to extend our acknowledgement to Gondar Agricultural Research Center and the Amhara Agricultural Research Institute for financially assisting this experiment. The authors would like to thank staff members of horticultural crops research case team and the research stations under Gondar Agricultural Research Center for their support in collecting seeds, managing experimental trials and collecting data.

\section{References}

Akcura, M. and Kaya, Y. (2008). Nonparametric stability methods for interpreting genotype by environment interaction of bread wheat genotypes (Triticum aestivum L.). Genet. Mol. Biol. 31(4): 906-913.

Bairwa, R., Sodha, R., Rajawat, B. (2012). Trachyspermum ammi, Pharmacogn. Rev. 6: 56-60.

Becker, H.C. (1981). Correlations among some statistical measures of phenotypic stability. Euphytica 30: 835840.

Becker, H.C. and Leon, J. (1988). Stability analysis in plant breeding. Plant Breeding. 101:1-23.

Branco, L.C. (2015). phenability: Nonparametric stability analysis. R package version 2.0. https://CRAN.Rproject.org/package $=$ phenability.

Dawit Abate, Asfaw Dereje, Kelebesa Urga (2003). Medicinal plants and other Useful plant in Ethiopia. Ethiopian health and nutrition research institute. Addis Abeba. pp: 18-19. 
Dwivedi, S., Mishra, R., Alava, S. (2012). Phytochemistry: pharmacological studies and traditional benefits of Trachyspermum ammi (Linn). Sprague. IJPLS. 3: 1705-1709.

Flores, F., Moreno, M.T., Cubero, J.I. (1998). A comparison of univariate and multivariate methods to analyze G $\times$ E interactions. Field Crops Res. 56: 271-286.

Fox, P.N., Skovmand, B., Thompson, B.K., Braun, H.J., Cormier, R. (1990). Yield and adaptation of hexaploid spring triticale. Euphytica 47: 57-64.

Gebru Hintsa and Fetien Abay (2013). Evaluation of bread wheat genotypes for their adaptability in wheat growing areas of Tigray Region, Northern Ethiopia. J. Biodivers. Endanger. Species. 1:100-104.

GenStat (2015). GenStat for Windows (18th Edition).VSN International, Hemel, Hempstead, UK.

Hailemichael Girma, Kifelew Habetewold, Mitiku Haimanot (2016). Spices research achievements, challenges, and future prospects in Ethiopia. Acad. Res. J. Agri. Sci. Res. 4: 9-17.

Heidaria, E.F., Rahimmalek, M., Mohammadia, S., Ehtemam, M.H. (2016). Genetic structure and diversity of ajowan (Trachyspermum ammi) populations based on molecular, morphological markers, and volatile oil content. Ind. Crops Prod. 92: 186-196.

Huehn, M. (1979). Beitrage zur erfassung der phanotypischen stabilitat.EDV. Med. Biol. 10: 112-117.

Huehn, M. (1990). Non-parametric measures of phenotypic stability: Part 1.Theory. Euphytica 47: 189-194.

Hussein, M.A., Bjornstad, A., Aastveit, A.H. (2000). SAS G $\times$ E STAB: a SAS program for computing genotype $\times$ environment stability statistics. Agron. J. 92: 454-459.

Kang, M.S. (1988). A rank-sum method for selecting high yielding, stable corn genotypes. Cereal Res. Commun.16: 113-115.

Kang, M.S. (1990). Understanding and utilization of genotype-by-environment interaction in plant breeding, in: Kang, M.S. (Ed.). Genotype-by-Environment, Interaction and Plant Breeding, Louisiana State University, Department of Agronomy, Baton Rouge.pp: 52-68.

Kaya Y. and Turkoz, M. (2016). Evaluation of genotype by environment interaction for grain yield in durum wheat using non-parametric stability statistics. Turk. J. Field Crops. 21(1): 51-59.

Magari R, and Kang, M.S. (1993). Genotype selection via a new yield stability statistic in maize yield trials. Euphytica 70: 105-111.

Mekbib Friew (2002). Simultaneous selection for high yield and stability in common bean (Phaseolus vulgaris L.) genotypes. J. Agric. Sci. (Camb.). 138: 249-253.

MoANR, Ministry of Agriculture and Natural Resource (2010). Agricultural Investment Potential of Ethiopia. Addis Abeba, Ethiopia.

MoANR, Ministry of Agriculture and Natural Resource (2003). Development of black cumin and white Cumin Production. Addis Abeba, Ethiopia.

MoANR, Ministry of Agriculture and Natural Resources (2017). Crop variety registration: Plant variety release, protection and seed quality control department. Addis Ababa, Ethiopia. Bull. 20.

Mohammadi R. and Amri. A. (2008). Comparison of parametric and non-parametric methods for selecting stable and adapted durum wheat genotypes in variable environments. Euphytica 159:419-432.

Mohammadi, R. and Ahmed, A. (2013). Genotype x environment interaction and genetic improvement for yield and yield stability of rainfed durum wheat in Iran. Euphytica 192: 227-249.

Mohammadi, R., Abdulah, A., Haghparast, R., Armion, M. (2007a). Interpreting genotype environment interactions for durum wheat grain yields using nonparametric methods. Euphytica 157:239-251.

Mohammadi, R., Abdulahi, A., Haghparast, R., Aghaee, M., Rostaee, M. (2007b). Nonparametric methods for evaluating of winter wheat genotypes in multi environment trials. World J. Agric. Sci. 3: 137-242.

Mohammadi, R., Aghaee M., Haghparast R., Pourdad, S.S.,Rostaii, M., Ansari, Y., Abdolahi, A., Amri. A. (2009). Association among non-parametric measures of phenotypic stability in four annual crops. M.E.R.J.P.S.B. 3: 20-24.

Nassar, R. and Huehn, M. (1987). Studies on estimation of phenotypic stability: tests of significance for nonparametric measures of phenotypic stability. Biometrics 43: 45-53.

Roostaei, M., Mohammadi, R., Amri, A. (2014). Rank correlation among different statistical models in ranking of winter wheat genotypes. Crop J. 2: 154-163.

Sabaghnia, N., Dehghani, H., Sabaghpour, S.H. (2006). Nonparametric methods for interpreting genotype x environment interaction of lentil genotypes. Crop Sci. 46:1100-1106.

SAS Institute (2002). SAS/STAT User's Guide.Vol. 9, 4th ed. SAS Inst., Cary, NC. pp. 1733-1901.

Segherloo, A.E., Sabaghpour, S.H., Dehghani , H., Kamrani, M. (2008). Non-parametric measures of phenotypic stability in chickpea genotypes (Cicer arietinum L.). Euphytica.162: 221-229.

Shah, S.H., Shah, S.M., Khan, M.I., Ahmed, M., Hussain, I., Eskridge, K.M. (2009). Nonparametric methods in combined heteroscedastic experiments for assessing stability of wheat genotypes in Pakistan. Pak. J. Bot. 41(2): 711-730.

Shukla, G.K. (1972). Some aspects of partitioning genotype environmental components of variability. Heredity 
28: 237-245.

Steel, R.G.D. and Torrie, J.H. (1980). Principles and procedures of statistics. McGraw Hill Book Company, NY.

Temesgen Tamene, Keneni Gemechu, Sefera Tadese, Jarso Mussa (2015). Yield stability and relationships among stability parameters in faba bean (Vicia faba L.) genotypes. Crop J. 3: 258-268.

Thennarasu, K. (1995). On certain non-parametric procedures for studying genotype-environment interactions and yield stability.PhD Thesis.PJ School, IARI, New Delhi, India.

Tomar, P. and Malik, C. (2014). Botanycultivation chemical constituents and genetic diversity in Trachyspermum ammi. L. an aromatic seed spice. LS: Int. J. Life Sci. 3: 114-123.

Truberg B and Huehn M. (2000). Contributions to the analysis of genotype x environment interactions: comparison of different parametric and non-parametric tests for interactions with emphasis on crossover interactions. J. Agronomy \& Crop Science 185: 267-274.

Yan, W. and Kang, M.S. (2003). GGE-biplot analysis: A graphical tool for breeders, geneticists, and agronomists.CRC Press, Boca Raton, FL.

Yong-jian, L., Chuan,D., Meng-liang, T., Er-liang, H.,Yubi,H. (2010). Yield stability of maize hybrids evaluated in maize regional trials in southwestern China using nonparametric methods. Agric. Sci. China. 9(10): 14131422.

Zarshenas, M.M., Moein, M., Samani, S.M., Petramfar, P. (2014). An overview on ajwain (Trachyspermum ammi) pharmacological effects; modern and traditional. J.N.R. 14:(1). 